Water Rock Interaction [WRI 14]

\title{
Modification to the flow properties of repository cement as a result of carbonation
}

\author{
G. Purser*, A.E. Milodowski, J.F. Harrington, C.A. Rochelle, A. Butcher, \\ D. Wagner
}

British Geological Survey, Environmental Science Centre, Keyworth, Nottingham, NG12 5GG, UK

\begin{abstract}
The current UK repository concept for low- and intermediate-level radioactive wastes involves using large quantities of cementitious materials for both construction and buffer/backfill. $\mathrm{CO}_{2}$ generated from degradation of waste organic material results in cement carbonation and associated mineralogical changes. Hydraulic and gas permeability tests were performed at $4 \mathrm{MPa}$ and $40^{\circ} \mathrm{C}$. Carbonation halved the permeability of Nirex Reference Vault Backfill (NRVB) cement under these repository conditions. Mineralogical changes occurred in a narrow zone along the leading edge of a migrating reaction front and decreased porosity. The small reduction in permeability (and slightly elevated pressures) that resulted is considered to have minor impact on the permeable characteristics of the NRVB.
\end{abstract}

(C) 2013 The Authors. Published by Elsevier B.V. Open access under CC BY-NC-ND license.

Selection and/or peer-review under responsibility of the Organizing and Scientific Committee of WRI $14-2013$

Keywords: cement carbonation; NRVB; carbon dioxide; permability.

\section{Introduction}

The current UK repository concept for low- and intermediate-level radioactive wastes involves using large quantities of cementitious materials for both construction and buffer/backfill. Degradation of organic materials will produce significant quantities of $\mathrm{CO}_{2}$, leading to the conversion of cement minerals to secondary phases, such as carbonates [1]. This will reduce the high $\mathrm{pH}$ buffering capacity of the cement and, consequently, reduce radionuclide retardation [1]. These reactions may also alter cement physical properties, changing permeability and strength. Nirex reference vault backfill (NRVB) cement [2] is specifically designed to allow fluid flow to prevent the build-up of pressure in the repository. This study quantifies changes in cement permeability in the presence of $\mathrm{CO}_{2}$ under repository conditions.

\footnotetext{
* Corresponding author. Tel.: 0044115 9363067; E-mail address: gemm@bgs.ac.uk.
} 


\section{Methods}

\subsection{Sample preparation and experimental set up}

Samples of NRVB were prepared in one batch as per Francis et al. [2], cured at $40^{\circ} \mathrm{C}$ for 28 days, and then stored in $\mathrm{Ca}(\mathrm{OH})_{2}$-saturated water at room temperature. They were sub-cored to produce samples for testing, of $49 \mathrm{~mm}$ diameter x $49 \mathrm{~mm}$ long. The final dimensions and sample weights were accurately measured using a Linear Tools electronic caliper and a Mettler AT460 digital balance.

The cylindrical samples were sandwiched between sintered filters (to aid fluid distribution) and end caps. A Teflon jacket was used to exclude the confining fluid. Volumetric flow rates into and out of the samples were controlled and monitored using a pair of ISCO-500HP, series D, syringe pumps operated from a single digital control unit linked to remotely operated LabView ${ }^{\mathrm{TM}}$ software (Fig. 1).

Data collection was performed every 2 minutes with a sub sample of this data being used for analysis. The tests were performed inside an oven at $40^{\circ} \mathrm{C}$. All samples were isotropically confined at $8 \mathrm{MPa}$ with a backpressure of $4 \mathrm{MPa}$. Two main tests are reported here; one partially carbonating a sample (NRVB1), and one fully carbonating a sample (NRVB-2) (Table 1). A typical test history comprised of a sequence of test stages, each designed to quantify the hydraulic and gas transport properties (Table 1).

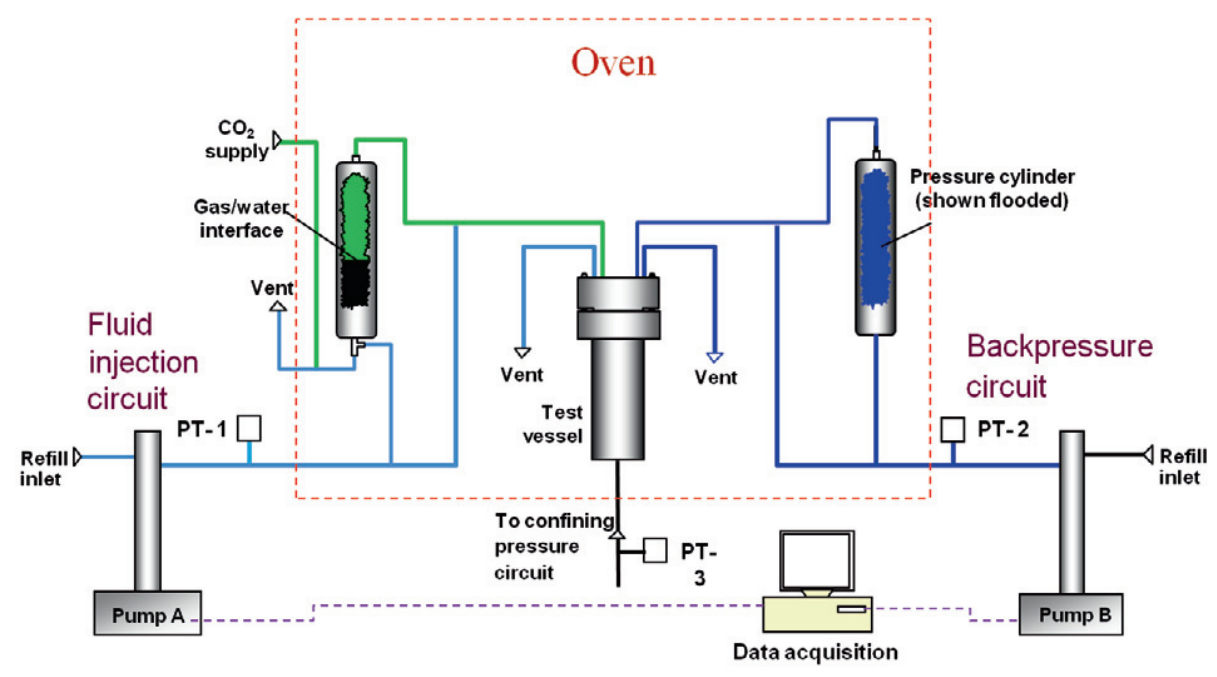

Fig. 1. Experimental set-up.

\subsection{Resaturation, Hydraulic and gas injection tests}

Initially injection and backpressure pumps were filled with $\mathrm{Ca}(\mathrm{OH})_{2}$-saturated water to re-equilibrate the sample. Injection and backpressure were maintained at $4 \mathrm{MPa}$ during core saturation. Once complete, hydraulic testing commenced by increasing and decreasing the injection flow rate in a stepwise manor, doubling and halving the flow rate from $2125 \mu \mathrm{L} / \mathrm{hr}$ to $8500 \mu \mathrm{L} / \mathrm{hr}$. Gas injection tests then proceeded. Two gases were used; nitrogen $\left(\mathrm{N}_{2}\right)$ to provide inert baseline data or $\mathrm{CO}_{2}$. These were accurately displaced from their interface vessels using deionised water, and through the NRVB samples. The initial pressure in both the injection and backpressure lines was set to a constant $4 \mathrm{MPa}$. Once each test system had stabilised, gas was injected into the NRVB sample at a constant flow rate of $1250 \mu 1 / \mathrm{hr}$. 
Table 1. Experimental test stages

\begin{tabular}{llllcccc}
\hline \multirow{2}{*}{ Test } & $\begin{array}{l}\text { Stage } \\
\text { number }\end{array}$ & Type of test & Fluid & $\begin{array}{l}\text { Hydraulic } \\
\text { permability } \\
\left(\mathrm{m}^{2}\right) \text { In }\end{array}$ & $\begin{array}{l}\text { Hydraulic } \\
\text { permability } \\
\left(\mathrm{m}^{2}\right) \text { Out }\end{array}$ & $\begin{array}{l}\text { Injection } \\
\text { pressure } \\
(\mathrm{MPa})\end{array}$ & $\begin{array}{l}\text { Back } \\
\text { pressure } \\
(\mathrm{MPa})\end{array}$ \\
\hline NRVB-1 & 1 & Resaturation & $\mathrm{Ca}(\mathrm{OH})_{2}$-saturated water & - & - & 3.98 & 3.99 \\
& $2-11$ & Hydraulic & $\mathrm{Ca}(\mathrm{OH})_{2}$-saturated water & $4.3 \times 10^{-17}$ & $4.3 \times 10^{-17}$ & - & 3.99 \\
& $12-13$ & Gas injection & $\mathrm{CO}_{2}$ & - & - & - & 3.99 \\
NRVB-2 & 1 & Resaturation & $\mathrm{Ca}(\mathrm{OH})_{2}$-saturated water & - & - & 3.99 & 4.00 \\
& $2-7$ & Hydraulic & $\mathrm{Ca}(\mathrm{OH})_{2}$-saturated water & $4.1 \times 10^{-17}$ & $4.1 \times 10^{-17}$ & - & 4.00 \\
& $8-9$ & Gas injection & $\mathrm{N}_{2}$ & $2.0 \times 10^{-19}$ & $2.0 \times 10^{-19}$ & 5.11 & 4.01 \\
& 10 & Resaturation & $\mathrm{Ca}(\mathrm{OH})_{2}$-saturated water & - & - & 3.99 & 4.00 \\
& $11-16$ & Hydraulic & $\mathrm{Ca}(\mathrm{OH})_{2}$-saturated water & $4.2 \times 10^{-17}$ & $4.2 \times 10^{-17}$ & - & 4.00 \\
& $17-18$ & Gas injection & $\mathrm{CO}_{2}$ & $1.0 \times 10^{-19}$ & $9.7 \times 10^{-20}$ & 5.93 & 4.00 \\
& 19 & Gas injection & $\mathrm{N}_{2}$ & $1.1 \times 10^{-19}$ & $1.1 \times 10^{-19}$ & 5.97 & 4.00 \\
\hline
\end{tabular}

\section{Results}

\subsection{Pressure and flow observations}

NRVB 1: Partial carbonation test

The hydraulic tests performed showed unaltered NRVB cement to be highly permeable compared to gas tests (Table 1). Previous studies of NRVB properties used deionised water [2] that resulted in a slightly lower permeability coefficient, around $1 \times 10^{-16} \mathrm{~m}^{2}$ in comparison to this study. Mineral dissolution of the NRVB by the deionised water may account for the difference in the values generated. On addition of $\mathrm{CO}_{2}$ gas, injection pressure initially increased to $4.83 \mathrm{MPa}$ before decreasing to 4.60 MPa. Subsequently, the injection pressure increased steeply to $5.00 \mathrm{MPa}$ at which point the $\mathrm{CO}_{2}$ supply was exhausted. Steady state was not reached during the experiment, and carbonation was only partial. Using an acid digestion method, $19.5 \mathrm{~g}$ of $\mathrm{CO}_{2}$ was found to have reacted with $158.2 \mathrm{~g}$ of NRVB cement core. This is comparable with the measured amount of $\mathrm{CO}_{2}$ injected using the high precision syringe pumps.

\section{NRVB-2: full carbonation test}

The hydraulic permeability data was found to be consistent with that of NRVB-1 (Table 1). Conductivity and permeability remained unaltered after the gas injection test with $\mathrm{N}_{2}$, confirming its nonreactivity with NRVB. Maximum test pressures were significantly higher during $\mathrm{CO}_{2}$ injection compared to those observed during $\mathrm{N}_{2}$ injection (Table 1). A marked breakthrough was signified by an increase in outflow after 21.7 days, and this continued until steady state conditions were achieved (Fig. 2a). A slow initial increase in outflow was observed between days 16-21, thought to be mainly water exiting the sample. Major gas breakthrough lagged behind the pressure peak, probably reflecting the complexity of the reaction fronts. Pre- and post-carbonation gas tests (using $\mathrm{N}_{2}$ ) clearly show a change in permeability leading to increased gas pressures observed (Table 1)

\subsection{Mineralogical observations}

The reacted cement core from experiment NRVB-1 displayed an obvious reaction front (associated with a marked colour change) that propagated half way along the length of the core (Fig. 2b). Small-scale variation in permeability along the sample length was determined using $\mathrm{N}_{2}$ injection micro-permeameter. 

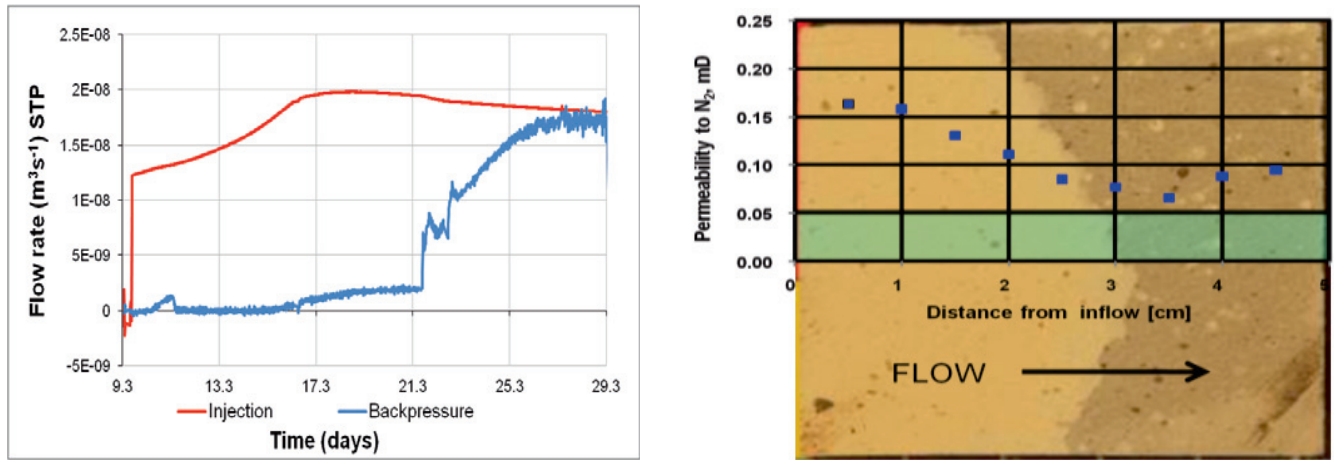

Fig. 2. (left) NRVB-2 gas test with $\mathrm{CO}_{2}$; (right) micropermeability variation through NRVB-1 sample section.

Measurements were taken after the core had been subject to vacuum desiccation, so are significantly higher than those in Table 1, but provided an indication of relative permeability change across sample. Permeability reduction occurs in a narrow zone at the leading edge of the visible alteration front. This accounts for the higher pressures during the NRVB-2 $\mathrm{CO}_{2}$ injection stage. Dissolution of CSH phases and portlandite, and leaching of $\mathrm{Ca}$, were observed just in front of the leading edge of the carbonation. This is associated with enhanced microporosity in the same region. Ca appears to have migrated towards the carbonation front where it is concentrated in a fine network of microfractures. BSEM-EDXA showed that the carbonated zone comprised a 'chicken-wire' meshwork of calcite-mineralised microfractures within a nanoporous matrix of amorphous silica and fine grained, patchy replacive calcite.

\section{Summary}

Carbonation of NRVB cement resulted in the formation of reaction fronts that travelled through the samples. Portlandite and $\mathrm{CSH}$ phase were destroyed, and $\mathrm{CaCO}_{3}$ and silica were formed. This process is associated with localised porosity increases, which are then variably filled with secondary $\mathrm{CaCO}_{3}$. A tight zone of significantly reduced permeability is created as the reaction front moves through the sample. This has the ability to 'armour' some regions of the cement, leading to isolated islands of unreacted NRVB and so reducing its total buffering capacity. Overall bulk gas permeability is halved on carbonation. While this behavior may not adversely affect the transport behaviour of NRVB, further work is required to understand the complex coupling between fluid flow, permeability and carbonation.

\section{Acknowledgements}

This work supported through the European Atomic Energy Community, FORGE project, Grant Agreement no230357 and the Nuclear Decommissioning Authority Radioactive Waste Management Directorate (NDA/RWMD).

\section{References}

[1] Crossland IG. The role of engineered barriers in a UK repository for intermediate level radioactive waste. Interdisciplinary Science Reviews 1998; 23(3): 269-280.

[2] Francis AJ, Cather R, Crossland IG. Development of the Nirex reference vault backfill; report on current status in 1994. Nirex Science Report S/97/014 1997. United Kingdon Nirex Limited, 57 p. 